\title{
Regenerative Medicine Approaches for Age-Related Muscle Loss and Sarcopenia: A Mini-Review
}

\author{
Juan Diego Naranjo ${ }^{a, c}$ Jenna L. Dziki ${ }^{a, b}$ Stephen F. Badylak ${ }^{a-c}$ \\ ${ }^{a}$ McGowan Institute for Regenerative Medicine and ${ }^{b}$ Department of Bioengineering, University of Pittsburgh, and \\ 'Department of Surgery, University of Pittsburgh School of Medicine, Pittsburgh, PA, USA
}

\section{Keywords}

Sarcopenia - Regenerative medicine - Stem cells · IGF-1 . Growth hormone - Vitamin D · Satellite cells · Myostatin . Urocortin II P Physical therapy

\begin{abstract}
Sarcopenia is a complex and multifactorial disease that includes a decrease in the number, structure and physiology of muscle fibers, and age-related muscle mass loss, and is associated with loss of strength, increased frailty, and increased risk for fractures and falls. Treatment options are suboptimal and consist of exercise and nutrition as the cornerstone of therapy. Current treatment principles involve identification and modification of risk factors to prevent the disease, but these efforts are of limited value to the elderly individuals currently affected by sarcopenia. The development of new and effective therapies for sarcopenia is challenging. Potential therapies can target one or more of the proposed multiple etiologies such as the loss of regenerative capacity of muscle, age-related changes in the expression of signaling molecules such as growth hormone, IGF-1, myostatin, and other endocrine signaling molecules, and age-related changes in muscle physiology like dener-
\end{abstract}

\section{KARGER}

(C) 2017 S. Karger AG, Basel

E-Mail karger@karger.com

www.karger.com/ger vation and mitochondrial dysfunction. The present paper reviews regenerative medicine strategies that seek to restore adequate skeletal muscle structure and function including exogenous delivery of cells and pharmacological therapies to induce myogenesis or reverse the physiologic changes that result in the disease. Approaches that modify the microenvironment to provide an environment conducive to reversal and mitigation of the disease represent a potential regenerative medicine approach that is discussed herein.

(c) 2017 S. Karger AG, Basel

\section{Introduction}

Aging is associated with the progressive and predictable changes that occur in the human body. All body systems are affected by the aging process, compromising both general health and quality of life. The musculoskeletal system is no exception. In healthy young individuals, skeletal muscle protein synthesis and degradation is a balanced, dynamic process typically involving no net change occurring in skeletal muscle mass $[1,2]$. However, muscle tissue mass is gradually lost with advancing age, with an

Stephen F. Badylak

McGowan Institute for Regenerative Medicine, University of Pittsburgh 450 Technology Drive Suite 300, Bridgeside Point II (BSP2)

Pittsburgh, PA 15219 (USA)

E-Mail badylaks@upmc.edu 
associated loss of strength, a condition referred to as sarcopenia. Sarcopenia affects up to $30 \%$ of older adults, 14 $33 \%$ for those that live in chronic-care institutions, and $10 \%$ of patients in acute hospital care [3]. Sarcopenia represents a major risk factor for adverse events associated with frailty, weakness, falls, immobility, functional decline, and institutionalization [4]. Sarcopenia is defined by the European Working Group on Sarcopenia as progressive and generalized loss of skeletal muscle mass and strength with a risk of adverse outcomes such as physical disability, frailty, poor quality of life, and death [3]. Alternative definitions for sarcopenia have been proposed, which include factors such as walking speed or grip strength in people with low muscle mass. These definitions have proven valuable, but cutoff values should be adjusted for each individual population. In September 2016, sarcopenia was recognized as a distinct disease entity and was assigned the ICD-10-CM (M62.84) code. This disease recognition is expected to lead to a greater interest in disease diagnosis by physicians, an increase in diagnostic tools for recognizing the disease, and an increased interest for developing therapies for the disease [5].

Current treatment strategies for sarcopenia can be broadly divided into preventative measures and those that mitigate progression of the disease after onset. Preventative measures focus on the identification and modification of risk factors for disease development in the elderly. Strategies to minimize the deleterious effects of sarcopenia include methods to decrease the risk factors for falls and provide assistance for the activities of daily living to prevent institutionalization, among others. $\mathrm{Nu}$ trition and exercise are the two fundamental tenants of treatment, but there is controversy regarding the relative clinical benefit of either approach. Disparate results are reported for these treatment methods likely due to the different protocols used in each study with the possibility of some being more effective than others. Nutritionbased approaches include supplementation of proteins, essential amino acids, and fatty acids. Exercise trials include resistance training and physical activity [reviewed in 3]. There is an obvious need for novel therapeutic strategies that consider both the inevitable systemic physiologic changes with aging and the specific changes that occur with skeletal muscle aging. Both factors contribute to loss of contractile muscle force. The present review provides an overview of healthy skeletal muscle physiology, the changes in skeletal muscle with age, and innovative regenerative medicine approaches that facilitate muscle regeneration in aged individuals.

Age-Related Muscle Loss and Sarcopenia

\section{Skeletal Muscle Anatomy, Physiology, and Acute Regeneration following Injury}

Skeletal muscle is composed of muscle fibers which are highly specialized to produce force and movement. These fibers are cylindrical in shape, range in diameter from 10 to $100 \mu \mathrm{m}$, contain multiple nuclei, mitochondria, and sarcomeres, and are surrounded by the basal lamina, i.e. the endomysium. Satellite cells represent the putative skeletal muscle progenitor cell type and reside between the basal lamina and the sarcolemma, though multiple cell types have been shown to provide myogenic potential, including perivascular stem cells [6-15]. Muscle fibers are arranged together in parallel and collectively form the muscle fascicle or fiber bundle which is encapsulated by a perimysium. A distinct muscle is formed by enveloping a large number of muscle fascicles in a thick collagenous external sheath extending from the tendons called the epimysium (Fig. 1). Multiple skeletal muscle fibers are innervated by a single a motor neuron (MU). Individual motor axons branch within muscle to synapse with different fibers over a wide area which helps promote even distribution of contractile force. The branching arrangement preserves muscle function even if individual MUs are damaged. The a MU and its associated muscle fibers are considered the smallest unit of force that can be activated in muscles to produce movement.

Skeletal muscle possesses an inherent capacity for regeneration following injury. This regenerative property is largely due to activation of resident satellite cells and is regulated in part by host innate immune responses, especially the macrophage response. Muscle injury is immediately followed by an inflammatory phase characterized by the recruitment of neutrophils and monocytes to the site of injury. Macrophages are activated and transition from a proinflammatory, M1-like phenotype that initiates skeletal muscle progenitor cell proliferation/expansion to a proremodeling, M2-like macrophage phenotype that is required for skeletal muscle progenitor cell mobilization and differentiation, deposition of new extracellular matrix (ECM), angiogenesis, and return to homeostasis. Disturbances in the responding stem/progenitor cell populations as well as the innate immune system and the microenvironment have been shown to contribute to sarcopenia [16]. Beyond aging, muscle wasting is also associated with chronic inflammatory diseases, including chronic obstructive pulmonary disease, muscular dystrophy, idiopathic myopathies, and rheumatoid arthritis, among others. Proinflammatory cytokines including IFNy, IL-1, TNF $\alpha$, IL-6, IL-18, and IL-8 have been shown

Gerontology 2017;63:580-589 DOI: $10.1159 / 000479278$ 
Fig. 1. Muscle fibers are cylindrical in shape, range in diameter from 10 to 100 $\mu \mathrm{m}$, contain multiple nuclei, mitochondria, and sarcomeres, and are surrounded by the endomysium. These fibers are arranged together in parallel and collectively form the muscle fascicle or fiber bundle which is encapsulated by a perimysium. A distinct muscle is formed by enveloping a large number of muscle fascicles in a thick collagenous external sheath extending from the tendons called the epimysium. Satellite cells represent the putative skeletal muscle progenitor cell type and reside between the basal lamina and the sarcolemma.

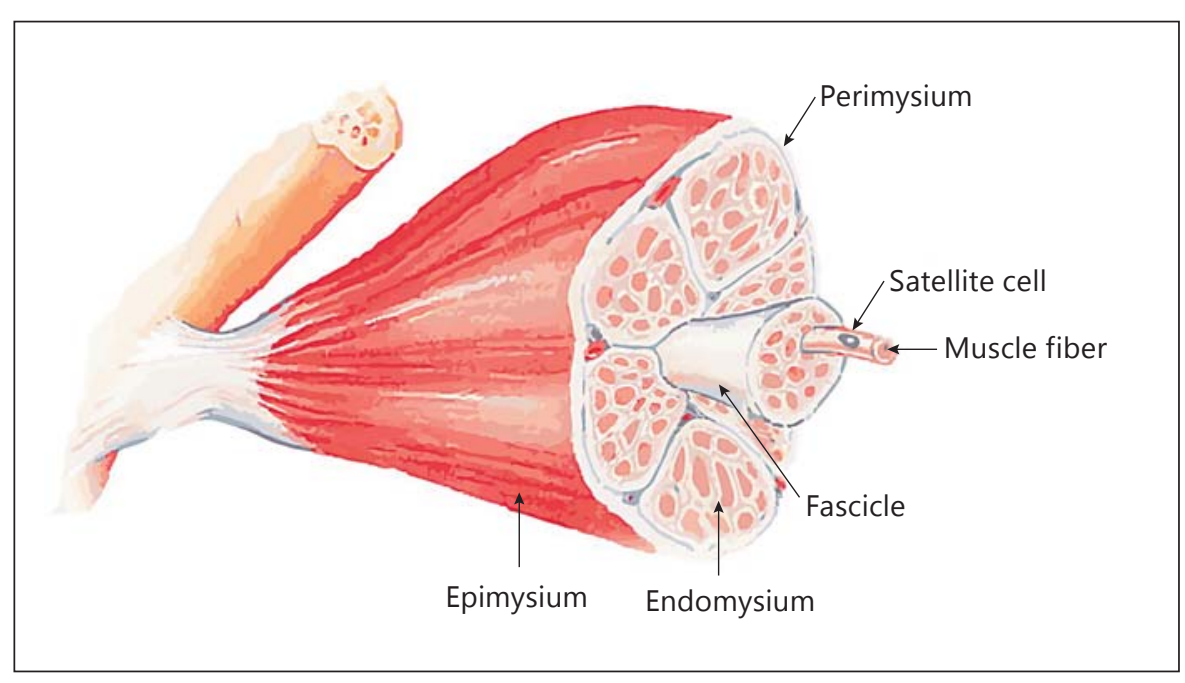

to be major contributors to muscle loss in these and other chronic inflammatory disease states. Deleterious effects of inflammation inhibit efficient skeletal muscle regeneration and lead to muscle atrophy [17].

\section{Pathophysiology of Sarcopenia}

The onset of sarcopenia typically results from a combination of risk factors and is associated with a decreased skeletal muscle fiber number $[18,19]$, changes in the cross-sectional area of the remaining fibers $[18,20,21]$, and systemic changes that alter normal muscle physiology. The potential contributing factors to the onset and progression of sarcopenia are reviewed below.

\section{Defects in Protein Trafficking, Degradation, and Removal}

The gradual and cumulative accumulation of nonfunctional muscle protein has been proposed as a potential mechanism by which sarcopenia occurs. This accumulation of nonfunctional protein is supported by the observation that the decrease in muscle strength is disproportionately greater than the decrease in muscle mass during the progression of sarcopenia. Potential causes of muscle strength mass and strength loss include defects in autophagy, ubiquitination, and lysosomal degradation, and decreased proteasome activity. Wohlgemuth et al. [22] showed an age-related impairment of autophagy that can be attenuated by caloric restriction alone or with voluntary exercise. Carnio et al. [23] demonstrated that inhibition of autophagy exacerbates aging phenotypes and has a major impact on neuromuscular synaptic function, muscle strength, and the life span of mice. Autophagy defects appear to relate to morphological changes in muscle fibers. For example, accumulation of p62/SQMT1, an indicator of lack of autophagy, is associated with smaller cross-sectional areas of muscle fibers when compared to p62/SQMT1-negative cells in aged mice [21].

Ineffective removal of nonfunctional proteins may be part of the etiology of the disease [24]. Similarly, oxidized proteins, which accumulate with advancing age, may not be as efficiently removed by normal ubiquitination and lysosomal degradation, resulting in the accumulation of lipofuscin and cross-linked proteins. Proteasome activity declines with age as the enzyme complex is progressively inhibited by oxidized and cross-linked protein aggregates. Thus, cellular aging in sarcopenia can be a result of mitochondrial oxidant production and a concomitant decline in proteolytic activity, both of which contribute to rapid accumulation of oxidized proteins, cellular dysfunction, and senescence [25].

\section{Mitochondrial Contribution to Sarcopenia}

Mitochondrial reactive oxygen species generation is increased in skeletal muscle during aging and is associated with impaired mitochondrial function and oxidative damage [26]. In healthy muscle, the potentially deleterious effects of reactive oxygen species are mitigated or regulated by expression of protective proteins [27]. This regulatory response is attenuated in aged mice and contributes to age-related loss of muscle mass and function [27]. Studies in rats and nonhuman primates have shown that mitochondrial DNA (mtDNA) mutations and deletions 
are increased in fibers from aged skeletal muscle, and these mutations are more frequent in muscles prone to sarcopenia [28].

mtDNA deletion mutations in skeletal muscle which clonally accumulate across individual fibers have been suggested as a mechanism for muscle wasting and associated decline in functional activity. Wang et al. [29] demonstrated that short, transient, systemic, double-strand breaks in mtDNA led to muscle wasting and a decline in locomotor activity in mice later in life with a significant decline in the number of satellite cells. It was later suggested that the contribution of mtDNA damage to sarcopenia could also involve the electron transport chain with an initial mtDNA mutation resulting in clonal accumulation of a mutation within the affected muscle fiber. Clonal accumulation of mutations within muscle fibers leads to alterations in the electron transport chain resulting in muscle fiber apoptosis and loss [30]. Herbst et al. [31] induced mitochondrial biogenesis with $\beta$-GPA (guanidinopropionic acid) pharmacologically in older-age mice which would promote clonal expansion of mitochondria and their already present mtDNA deletions/mutations. Treatment with $\beta$-GPA increased the number abnormal fibers in the electron transport chain and fibrosis and decreased muscle fiber number and mass. Increased numbers of mtDNA mutations have been shown in mice, rats [28], nonhuman primates [32], and humans. [33].

\section{Loss of the Inherent Regenerative Capacity}

The series of well-defined processes that promote myogenic regeneration include initial myofiber necrosis, infiltration of neutrophils and proinflammatory macrophages, myogenic progenitor cell proliferation, a transition toward proremodeling macrophages, myogenic progenitor cell differentiation, and eventual fusion and reinnervation of regenerated muscle fibers [34]. Age-related changes in both the microenvironment and the myoblasts can hinder these important processes in individuals with sarcopenia.

Barberi et al. [16] showed that with age the changes in the microenvironmental niche are associated with: (1) satellite cells that are delayed in their response to activating stimuli in a suboptimal environment, and (2) isochronic conditions that can inhibit satellite cell differentiation. The pronounced loss of satellite cells in sarcopenic muscle [35] has led to the hypothesis of a cause-effect relationship between satellite cell number and muscle function with sarcopenia. However, murine studies have not consistently supported this theory [36]. Furthermore, Fry et al. [36] have shown that selective depletion of satel-

Age-Related Muscle Loss and Sarcopenia lite cells did not contribute to sarcopenia, suggesting that satellite cell replenishment may not necessarily benefit affected patients.

Shefer et al. [37] demonstrated that although there may be a reduction in the number of satellite cells present in an aging environment, it is more likely that their impaired regenerative potential is caused by the environment and not by an inherent change in the cells themselves. Carlson et al. [38] disclosed through heterochronic experiments that old muscle cells can successfully regenerate when implanted into a younger host and vice versa. This process was validated further in experiments by Conboy et al. [39], which indicated that a mutual circulatory system can rejuvenate aged progenitor cells simply by exposure to a younger environment.

It is important to recognize the importance of the immune system in skeletal muscle regeneration. Teixeira et al. [40] reported that neutrophil depletion inhibited muscle regeneration, and Bencze et al. [41], among others, have revealed that the acute regenerative response is highly regulated by the responding macrophage population. The presence of proinflammatory versus proremodeling macrophages changes the dynamics of muscle regeneration. Without an appropriate temporal macrophage phenotype transition, skeletal muscle regeneration does not occur [42].

\section{Denervation Atrophy}

One potential cause of sarcopenia is the loss of a MU input to the muscle [43]. As the number of functional motor units decreases with age, there is an enlargement of the cross-sectional area of the remaining units [44]. This motor unit remodeling occurs by selective denervation of muscle fibers, mainly fast-twitch (type IIB) fibers, followed by re-innervation from juxtaposed innervated units [45]. This process leads to a net loss of fibers and functional motor units and to an increase in motor unit size and single action potential amplitude [46]. It is not clear if the loss of MUs precedes the fiber number loss, or if the opposite occurs. Age-related loss of muscle mass has been shown to involve a greater loss of fast-fiber crosssectional area [19], which is accompanied by a reduction in fast MUs [46]. Skeletal muscle appears to compensate for this reduction in MUs by hypertrophy of remaining smaller and slower MUs [46], thus partially explaining the presentation of slow muscle fibers in aging. Reduction in motor unit number is associated with histological changes such as angulated fibers and fiber-type clumping, both of which are suggestive of neuronal remodeling in elderly people [47]. It should be noted, however, that only

Gerontology 2017;63:580-589 DOI: $10.1159 / 000479278$ 
$11 \%$ of specific force decrements are due to denervated fibers in rats, suggesting that other factors contribute to the development of sarcopenia [48].

Other neurologic changes can contribute to the development of sarcopenia, including a decrease in the number of nerve terminals, fragmentation of the neuromuscular junction, decrease in the neurotransmitter release, and a decreased number of acetylcholine receptors.

\section{Endocrine Changes in Sarcopenia}

Age-related changes in the endocrine system have been linked to sarcopenia; a finding that has both therapeutic and causation implications [reviewed in 49]. Serum testosterone levels decline with age in both men and women, and this decline is associated with decreased muscle mass and strength, especially in men [50]. Testosterone is the main anabolic hormone for protein synthesis in skeletal muscle and has been shown to promote muscle regeneration via satellite cell activation [49]. In several multicenter trials called "The Testosterone Trials", 790 men of at least 65 years of age were treated with testosterone gel or placebo gel for 12 months. The percentage of men who had an increase of at least $50 \mathrm{~m}$ in 6-min walking distance was significant when participants of the 3 trials were compared $(20.5 \%$ after testosterone vs. $12.6 \%$ after placebo, $p=0.003)$. Treatment was well tolerated and with a similar rate of adverse events in the two groups [51].

Similarly, in females, menopause is associated with a marked reduction in estrogen levels and an accelerated decline in muscle mass and strength [52]. Estrogens have beneficial effects on muscle strength and are known to modulate the inflammatory response and response to injury in skeletal muscle through satellite cell activation and proliferation [53]. Hormone replacement therapy in women appears to delay muscle loss with age and accumulation and increase in skeletal muscle fat [54].

\section{Vitamin D, Insulin, and IGF-1: Implications in the}

\section{Pathogenesis of Sarcopenia}

Vitamin D is typically administered for skeletal disorders, but modulation of muscle morphology, muscle strength, and physical performance has also been reported [55]. The mechanism by which vitamin $\mathrm{D}$ exerts protective effects in skeletal muscle remains unclear. Vitamin $\mathrm{D}$ supplementation in vitamin $\mathrm{D}$-deficient elderly people resulted in improved muscle strength ability and a reduction in falls and fractures [56].

Insulin sensitivity declines with age in several tissues, including skeletal muscles [57]. Insulin decreases protein degradation and stimulates protein synthesis [58]. An increase in insulin resistance with age could result in inhibition of the nitric oxide cascade which would result in a lower absorption of amino acids for protein synthesis. Diabetes mellitus is a condition that is frequently associated with sarcopenia in the elderly [59]. Diabetes mellitus promotes the reduction in muscle mass and strength through hyperglycemia, obesity, and increased general inflammation, all of which are known risk factors for sarcopenia [59].

Growth hormone and insulin-like growth factor-1 (IGF-1) are potent stimulators of cell proliferation, and both factors progressively decrease with age in adults due to progressive functional impairment of the hypothalamic-pituitary axis. Growth hormone production has been reported to decline with age with a parallel decline in IGF-1 secretion [60]; this decline contributes to several detrimental phenotypes of aging. IGF-1 is the primary mediator of muscle repair and growth which stimulates satellite cell proliferation and muscle protein synthesis, inhibits proteolysis, and counteracts inflammation and fibrosis [61]. Decreased serum IGF-1 levels and low bioavailable testosterone are independently associated with the risk of developing sarcopenia [62].

\section{Current and Potential Novel Approaches to Sarcopenia Treatment}

\section{Exogenous Stem/Progenitor Cell Delivery}

Prior to age-related changes, skeletal muscle tissue maintains a remarkable capacity to regenerate following acute injury. After injury, the quiescent stem cells that reside between the basal lamina and sarcolemma are activated, proliferate, and replenish the satellite cell pool or fuse and differentiate to form multinucleated myofibers. The association of sarcopenia with loss of these functional contractile myofiber units has logically prompted the investigation of utilizing exogenous delivery of stem/progenitor cells to repopulate the satellite cell pool and stimulate myogenesis. To date, little success has been achieved by exogenous stem cell delivery. Table 1 lists the different cells that have been evaluated for skeletal muscle repair. However, stem-cell-based approaches for skeletal muscle regeneration are plagued with issues of deliverability and in vitro expansion. While preclinical studies continue to show promising results, the clinical utility of stem-cellbased approaches must circumvent not only technical but also economic and regulatory hurdles prior to their widespread adoption as a therapy for sarcopenia. 
Table 1. Stem-cell-based strategies for myofiber regeneration

\begin{tabular}{|c|c|c|c|}
\hline Cell type & Description & $\begin{array}{l}\text { Progress towards therapeutic } \\
\text { potential }\end{array}$ & Challenges \\
\hline Satellite cells $[6,7]$ & $\begin{array}{l}\text { Adult stem cells } \\
\text { Express Pax7 transcription } \\
\text { factor } \\
\text { Necessary for proliferation and } \\
\text { maintenance of muscle stem cell } \\
\text { pool }\end{array}$ & $\begin{array}{l}50 \text { years from first identification to a } \\
\text { pure cell isolation. } \\
\text { Surface markers identified for } \\
\text { satellite cell isolation are not } \\
\text { necessarily reflected in human } \\
\text { physiology } \\
\text { Need for optimized isolation and } \\
\text { more efficient expansion }\end{array}$ & $\begin{array}{l}\text { Very difficult to isolate and } \\
\text { expand in culture } \\
\text { Limited engraftment efficiency }\end{array}$ \\
\hline $\begin{array}{l}\text { Muscle-derived stem } \\
\text { cells }[8,9]\end{array}$ & $\begin{array}{l}\text { Adult stem cells } \\
\text { Identified in the interstitial space } \\
\text { in mice } \\
\text { Nonadherent cell population }\end{array}$ & $\begin{array}{l}\text { Improve muscle regeneration as } \\
\text { measured by histology in preclinical } \\
\text { murine models } \\
\text { Can be expanded in vitro up to } 30 \\
\text { passages while retaining myogenic } \\
\text { capacity }\end{array}$ & $\begin{array}{l}\text { Poor engraftment efficiency } \\
\text { No functional improvement } \\
\text { despite histological } \\
\text { improvement }\end{array}$ \\
\hline $\begin{array}{l}\text { Perivascular stem } \\
\text { cells }[10,11]\end{array}$ & $\begin{array}{l}\text { Adult stem cells } \\
\text { Found in muscle microvasculature } \\
\text { typically vessel associated } \\
\text { CD146+/NG2+/ALP+ } \\
\text { Express satellite cell markers } \\
\text { Assume satellite cell position after } \\
\text { injection }\end{array}$ & $\begin{array}{l}\text { Currently ongoing phase I/II clinical } \\
\text { trial for pediatric muscular dystrophy } \\
\text { Can be cultured up to } 20 \text { passages } \\
\text { while retaining myogenic capacity } \\
\text { Better engraftment efficiency than } \\
\text { satellite cells } \\
\text { Improve muscle function and } \\
\text { morphology }\end{array}$ & $\begin{array}{l}\text { Variability in in vitro } \\
\text { scalability gives them a finite } \\
\text { culture life span }\end{array}$ \\
\hline $\begin{array}{l}\text { Embryonic stem } \\
\text { cells }[12-14]\end{array}$ & $\begin{array}{l}\text { Pluripotent cells isolated from } \\
\text { inner cell mass of blastocyst }\end{array}$ & $\begin{array}{l}\text { Generation of large quantities in } \\
\text { vitro is possible } \\
\text { Engraftment ability has been } \\
\text { demonstrated in murine models }\end{array}$ & $\begin{array}{l}\text { Difficult to recapitulate the } \\
\text { skeletal muscle lineage in vitro } \\
\text { Potential immunologic } \\
\text { mismatch } \\
\text { Ethical concerns }\end{array}$ \\
\hline $\begin{array}{l}\text { Induced } \\
\text { pluripotent stem } \\
\text { cells (iPSC) [15] }\end{array}$ & $\begin{array}{l}\text { Genetically reprogrammed } \\
\text { somatic cells inducing a } \\
\text { pluripotent state }\end{array}$ & $\begin{array}{l}\text { Generation of Pax7+iPSCs is } \\
\text { possible } \\
\text { Generation of functional, human } \\
\text { skeletal myogenic progenitors has } \\
\text { been accomplished } \\
\text { Promote skeletal muscle regeneration } \\
\text { and functional improvements }\end{array}$ & $\begin{array}{l}\text { Requirement for genetic } \\
\text { correction } \\
\text { Risk of tumor generation }\end{array}$ \\
\hline
\end{tabular}

\section{Biologic Scaffolds}

Technical, regulatory, and economic issues have prevented timely translation of both stem-cell-based and pharmacological approaches to sarcopenia treatment. Inherently, skeletal muscle tissue has the ability to regenerate following acute injury, a property mostly attributed to the activity of satellite cells. However, it is becoming better understood that, in fact, the microenvironmental niche plays a significant role in contributing to the proliferative capacity of satellite cells and regeneration of skeletal muscle as a whole [16]. When skeletal muscle regenerative capacity is impeded, it is likely due, at least in part, to the loss of inherent signals that contribute to skeletal muscle regeneration in healthy tissue.

The evidence that changing the environment of aged myogenic progenitor cells can promote skeletal muscle regeneration is overwhelming. Moreover, clinical evidence indicates that mother nature's ideal microenvironment, healthy ECM in the form of a biologic scaffolds, promotes myogenesis in patients with volumetric muscle loss. In studies by Dziki et al. [63], the resultant muscle formation was not only histologically similar to that of uninjured muscle tissue, but patients treated with ECM bioscaffolds demonstrated notable strength and func-

Age-Related Muscle Loss and Sarcopenia 
tional improvements in addition to electromyographic improvement. Furthermore, ECM bioscaffolds have consistently been associated with a more favorable macrophage activation state transition in myogenic animal models [64]. Therefore, ECM bioscaffolds may represent an attractive solution for the treatment of age-related muscle loss. By providing the appropriate tissue niche and directing the macrophage response, ECM bioscaffolds can alter the default response to skeletal muscle injury and may provide an inductive template for facilitating muscle regeneration in an elderly host.

Although bioscaffolds have been implanted by invasive surgical procedures, minimally invasive delivery of the bioactive components of these bioscaffolds is possible. ECM hydrogels, which retain the composition and bioactivity of the intact ECM, would enable minimally invasive delivery of ECM via syringes or catheters [65]. Matrixbound nanovesicles have recently been identified within ECM bioscaffolds. These nanosized particles appear to be one of the main signaling mechanisms by which biologic effects are elicited within tissue. These matrix-bound vesicles have great potential as a minimally invasive treatment strategy [65].

\section{Pharmacological Approaches}

Pharmacological approaches to muscle regeneration have traditionally focused upon the delivery of anti-inflammatory drugs, steroids, hormones, and growth factors, for example. These approaches may hold promise in reverting the functional decline of sarcopenia or improving outcomes, but they do not specifically target myogenesis or directly affect the restoration tissue function. Drug delivery methods remain a significant obstacle. Systemic delivery of pharmaceuticals limits their efficacy due to the requirement of a suboptimal dose to avoid toxicity and other systemic side effects. The short half-life of most pharmaceuticals renders direct injection of the drug into the targeted muscle compartment generally ineffective [66]. Controlled drug delivery approaches have been the subject of active investigation in an attempt to deliver the appropriate dose of promising drugs to promote myogenesis.

Recently, it has been shown that a particular peptide expressed in the central nervous system and peripheral tissues, urocortin II, has potential as a therapeutic agent for muscle loss due to sarcopenia [67]. The link between urocortin II and muscle loss due to aging involves the relationship between sarcopenia, insulin resistance, obesity, and diabetes. Skeletal muscle relies heavily upon glucose as an energy source. Because of the mass of skeletal muscle, insulin resistance has substantial systemic effects for this tissue [68]. Insulin-associated accretion of muscle mass has established a link between molecules like urocortin II, vitamin D, and myostatin to age-related muscle loss. The potential of insulin resistance in muscle tissue and sarcopenia to present as comorbidities may help elucidate overlapping dysregularities in each case and contribute to better understanding of sarcopenia and the development of improved pharmacological therapies.

Myostatin is an autocrine cytokine that inhibits muscle development and is expressed exclusively in skeletal muscle, preferentially in fast-type skeletal muscle fibers [69]. In a study that compared wild-type versus myostatin-null mice, myostatin was shown to play an active role in myogenesis regulation during aging [70]. The administration of a myostatin antagonist produces a shortterm blockade of myostatin and an associated significant enhancement of muscle regeneration in aged mice after injury and during sarcopenia. Antagonism of myostatin was associated with satellite cell activation, increased Pax7 and MyoD levels, and greater myoblast and macrophage cell migration, all of which contribute to enhanced muscle regeneration after notexin injury in aged mice [71]. In men, higher serum myostatin was independently associated with higher odds for sarcopenia [72], which suggests myostatin antagonists as a potential therapy for sarcopenia.

\section{Muscle Loading and Exercise}

To date, the primary treatment option for sarcopenia is exercise, specifically load-bearing activities including resistance or strength training. Resistance exercise is a powerful anabolic stimulus that can modify the expression of critical regulatory genes associated with skeletal muscle growth and function, but this response may be impaired in aged individuals [24]. Incorporation of early mechanical stimulation in the form of resistance exercise is considered a critical determinant of ECM-bioscaffoldmediated skeletal muscle repair, but mechanical stimulation alone is increasingly becoming a therapeutic focus of skeletal muscle regeneration. White et al. [73] specifically showed that voluntary resistance wheel exercise significantly increased markers of mitochondrial and autophagosomal pathways and prevented age-related muscle wasting in 23-month-old mice. Mounting evidence has shown the importance of incorporation of mechanical loading to promote not only myogenesis, but also macrophage activation. Cezar et al. [74] corroborated the broad clinical utility of mechanical loading in the field of regenerative medicine by showing the ability of mechanical
586

Gerontology 2017;63:580-589

DOI: $10.1159 / 000479278$
Naranjo/Dziki/Badylak 
stimulation alone, in a biologic-free muscle-regenerating system, to promote myogenesis in a rodent model of ischemic muscle injury. Though perhaps not an ultimate solution, the combination of focused mechanical loading with stem-cell-, pharmaceutical-, or biomaterial-based therapies could potentially enhance regenerative outcomes.

\section{Conclusions}

Finding effective treatment strategies for sarcopenia will likely involve a multidisciplinary approach due to the complex etiology of the disease. Identification of the role of cytokines and small molecules, cellular metabolism, and endocrine-related changes have helped gain a better understanding of sarcopenia cause and progression. Regenerative medicine strategies, including the use of an acellular, inductive approach that tailors the microenvironment and considers the many cell types involved in efficient skeletal muscle regeneration, may provide a promising alternative to traditionally utilized therapies including stem cell delivery, pharmacological treatment, and physical rehabilitation. Likely, a combination of these approaches, among others, can provide improved outcomes for patients suffering from age-related muscle loss.

\section{Disclosure Statement}

The authors have no conflict of interest to declare.

\section{References}

1 Balagopal P, Rooyackers OE, Adey DB, Ades PA, Nair KS: Effects of aging on in vivo synthesis of skeletal muscle myosin heavy-chain and sarcoplasmic protein in humans. Am J Physiol 1997;273(4 pt 1):E790-E800.

2 Volpi E, Sheffield-Moore M, Rasmussen BB, Wolfe RR: Basal muscle amino acid kinetics and protein synthesis in healthy young and older men. JAMA 2001;286:1206-1212.

3 Cruz-Jentoft AJ, Landi F, Schneider SM, Zuniga C, Arai H, Boirie Y, Chen LK, Fielding RA, Martin FC, Michel JP, Sieber C, Stout JR, Studenski SA, Vellas B, Woo J, Zamboni M, Cederholm T: Prevalence of and interventions for sarcopenia in ageing adults: a systematic review. Report of the International Sarcopenia Initiative (EWGSOP and IWGS). Age Ageing 2014;43:748-759.

4 Batsis JA, Mackenzie TA, Barre LK, LopezJimenez F, Bartels SJ: Sarcopenia, sarcopenic obesity and mortality in older adults: results from the National Health and Nutrition Examination Survey III. Eur J Clin Nutr 2014;68: 1001-1007.

5 Anker SD, Morley JE, von Haehling S: Welcome to the ICD-10 code for sarcopenia. J Cachexia Sarcopenia Muscle 2016;7:512-514.

6 Collins CA, Olsen I, Zammit PS, Heslop L, Petrie A, Partridge TA, Morgan JE: Stem cell function, self-renewal, and behavioral heterogeneity of cells from the adult muscle satellite cell niche. Cell 2005;122:289-301.

7 Montarras D, Morgan J, Collins C, Relaix F, Zaffran S, Cumano A, Partridge T, Buckingham M: Direct isolation of satellite cells for skeletal muscle regeneration. Science 2005; 309:2064-2067.

8 Qu-Petersen Z, Deasy B, Jankowski R, Ikezawa M, Cummins J, Pruchnic R, Mytinger J, Cao B, Gates C, Wernig A, Huard J: Identifi- cation of a novel population of muscle stem cells in mice: potential for muscle regeneration. J Cell Biol 2002;157:851-864.

9 Mueller GM, O’Day T, Watchko JF, Ontell M: Effect of injecting primary myoblasts versus putative muscle-derived stem cells on mass and force generation in mdx mice. Hum Gene Ther 2002;13:1081-1090.

10 Dellavalle A, Maroli G, Covarello D, Azzoni E, Innocenzi A, Perani L, Antonini S, Sambasivan R, Brunelli S, Tajbakhsh S, Cossu G: Pericytes resident in postnatal skeletal muscle differentiate into muscle fibres and generate satellite cells. Nat Commun 2011;2:499.

11 Dellavalle A, Sampaolesi M, Tonlorenzi R, Tagliafico E, Sacchetti B, Perani L, Innocenzi A, Galvez BG, Messina G, Morosetti R, Li S, Belicchi M, Peretti G, Chamberlain JS, Wright WE, Torrente Y, Ferrari S, Bianco P, Cossu G: Pericytes of human skeletal muscle are myogenic precursors distinct from satellite cells. Nat Cell Biol 2007;9:255-267.

12 Evans MJ, Kaufman MH: Establishment in culture of pluripotential cells from mouse embryos. Nature 1981;292:154-156.

13 Rohwedel J, Maltsev V, Bober E, Arnold HH, Hescheler J, Wobus AM: Muscle cell differentiation of embryonic stem cells reflects myogenesis in vivo: developmentally regulated expression of myogenic determination genes and functional expression of ionic currents. Dev Biol 1994;164:87-101.

14 Barberi T, Bradbury M, Dincer Z, Panagiotakos G, Socci ND, Studer L: Derivation of engraftable skeletal myoblasts from human embryonic stem cells. Nat Med 2007;13:642648.

15 Mizuno Y, Chang H, Umeda K, Niwa A, Iwasa T, Awaya T, Fukada S, Yamamoto H, Yamanaka S, Nakahata T, Heike T: Generation of skeletal muscle stem/progenitor cells from murine induced pluripotent stem cells. FASEB J 2010;24:2245-2253.

16 Barberi L, Scicchitano BM, De Rossi M, Bigot A, Duguez S, Wielgosik A, Stewart C, McPhee J, Conte M, Narici M, Franceschi C, Mouly V, Butler-Browne G, Musaro A: Age-dependent alteration in muscle regeneration: the critical role of tissue niche. Biogerontology 2013;14: 273-292.

17 Londhe P, Guttridge DC: Inflammation induced loss of skeletal muscle. Bone 2015;80: 131-142.

18 Kramer IF, Snijders T, Smeets JS, Leenders M, van Kranenburg J, den Hoed M, Verdijk LB, Poeze M, van Loon LJ: Extensive type II muscle fiber atrophy in elderly female hip fracture patients. J Gerontol A Biol Sci Med Sci 2017, Epub ahead of print.

19 Lexell J, Taylor CC, Sjostrom M: What is the cause of the ageing atrophy? Total number, size and proportion of different fiber types studied in whole vastus lateralis muscle from 15- to 83 -year-old men. J Neurol Sci 1988;84: 275-294.

20 Aniansson A, Hedberg M, Henning GB, Grimby G: Muscle morphology, enzymatic activity, and muscle strength in elderly men: a follow-up study. Muscle Nerve 1986;9:585591.

21 Sakuma K, Kinoshita M, Ito Y, Aizawa M, Aoi W, Yamaguchi A: p62/SQSTM1 but not LC3 is accumulated in sarcopenic muscle of mice. J Cachexia Sarcopenia Muscle 2016;7:204212.

22 Wohlgemuth SE, Seo AY, Marzetti E, Lees HA, Leeuwenburgh C: Skeletal muscle autophagy and apoptosis during aging: effects of calorie restriction and life-long exercise. Exp Gerontol 2010;45:138-148. 
23 Carnio S, LoVerso F, Baraibar MA, Longa E, Khan MM, Maffei M, Reischl M, Canepari M, Loefler S, Kern H, Blaauw B, Friguet B, Bottinelli R, Rudolf R, Sandri M: Autophagy impairment in muscle induces neuromuscular junction degeneration and precocious aging. Cell Rep 2014;8:1509-1521.

24 Marcell TJ: Sarcopenia: causes, consequences, and preventions. J Gerontol A Biol Sci Med Sci 2003;58:M911-M916.

25 Grune T, Shringarpure R, Sitte N, Davies K: Age-related changes in protein oxidation and proteolysis in mammalian cells. J Gerontol A Biol Sci Med Sci 2001;56:B459-B467.

26 Vasilaki A, Mansouri A, Van Remmen H, van der Meulen JH, Larkin L, Richardson AG, McArdle A, Faulkner JA, Jackson MJ: Free radical generation by skeletal muscle of adult and old mice: effect of contractile activity. Aging Cell 2006;5:109-117.

27 Jackson MJ, McArdle A: Age-related changes in skeletal muscle reactive oxygen species generation and adaptive responses to reactive oxygen species. J Physiol 2011;589(pt 9):21392145.

28 Bua EA, McKiernan SH, Wanagat J, McKenzie D, Aiken JM: Mitochondrial abnormalities are more frequent in muscles undergoing sarcopenia. J Appl Physiol (1985) 2002;92: 2617-2624

29 Wang X, Pickrell AM, Rossi SG, Pinto M, Dillon LM, Hida A, Rotundo RL, Moraes CT: Transient systemic mtDNA damage leads to muscle wasting by reducing the satellite cell pool. Hum Mol Genet 2013;22:3976-3986.

30 Cheema N, Herbst A, McKenzie D, Aiken JM: Apoptosis and necrosis mediate skeletal muscle fiber loss in age-induced mitochondrial enzymatic abnormalities. Aging Cell 2015;14: 1085-1093.

31 Herbst A, Wanagat J, Cheema N, Widjaja K, McKenzie D, Aiken JM: Latent mitochondrial DNA deletion mutations drive muscle fiber loss at old age. Aging Cell 2016, Epub ahead of print.

32 Lopez ME, Van Zeeland NL, Dahl DB, Weindruch R, Aiken JM: Cellular phenotypes of age-associated skeletal muscle mitochondrial abnormalities in rhesus monkeys. Mutat Res 2000;452:123-138.

33 Wang Y, Michikawa Y, Mallidis C, Bai Y, Woodhouse L, Yarasheski KE, Miller CA, Askanas V, Engel WK, Bhasin S, Attardi G: Muscle-specific mutations accumulate with aging in critical human mtDNA control sites for replication. Proc Natl Acad Sci USA 2001; 98:4022-4027.

34 Tidball JG, Dorshkind K, Wehling-Henricks M: Shared signaling systems in myeloid cellmediated muscle regeneration. Development 2014;141:1184-1196.

35 Zwetsloot KA, Childs TE, Gilpin LT, Booth FW: Non-passaged muscle precursor cells from 32-month old rat skeletal muscle have delayed proliferation and differentiation. Cell Prolif 2013;46:45-57.
36 Fry CS, Lee JD, Mula J, Kirby TJ, Jackson JR, Liu F, Yang L, Mendias CL, DupontVersteegden EE, McCarthy JJ, Peterson CA: Inducible depletion of satellite cells in adult, sedentary mice impairs muscle regenerative capacity without affecting sarcopenia. Nat Med 2015;21:76-80.

37 Shefer G, Rauner G, Stuelsatz P, Benayahu D, Yablonka-Reuveni Z: Moderate-intensity treadmill running promotes expansion of the satellite cell pool in young and old mice. FEBS J 2013;280:4063-4073.

38 Carlson BM, Dedkov EI, Borisov AB, Faulkner JA: Skeletal muscle regeneration in very old rats. J Gerontol A Biol Sci Med Sci 2001; 56:B224-B233.

39 Conboy IM, Conboy MJ, Wagers AJ, Girma ER, Weissman IL, Rando TA: Rejuvenation of aged progenitor cells by exposure to a young systemic environment. Nature 2005;433:760764.

40 Teixeira CF, Zamuner SR, Zuliani JP, Fernandes CM, Cruz-Hofling MA, Fernandes I, Chaves F, Gutierrez JM: Neutrophils do not contribute to local tissue damage, but play a key role in skeletal muscle regeneration, in mice injected with Bothrops asper snake venom. Muscle Nerve 2003;28:449-459.

41 Bencze M, Negroni E, Vallese D, YacoubYoussef H, Chaouch S, Wolff A, Aamiri A, Di Santo JP, Chazaud B, Butler-Browne G, Savino W, Mouly V, Riederer I: Proinflammatory macrophages enhance the regenerative capacity of human myoblasts by modifying their kinetics of proliferation and differentiation. Mol Ther 2012;20:2168-2179.

42 Deng B, Wehling-Henricks M, Villalta SA, Wang Y, Tidball JG: IL-10 triggers changes in macrophage phenotype that promote muscle growth and regeneration. J Immunol 2012; 189:3669-3680.

43 Brown WF: A method for estimating the number of motor units in thenar muscles and the changes in motor unit count with ageing. J Neurol Neurosurg Psychiatry 1972;35:845852.

44 Gundersen K: Determination of muscle contractile properties: the importance of the nerve. Acta Physiol Scand 1998;162:333-341.

45 Brooks SV, Faulkner JA: Skeletal muscle weakness in old age: underlying mechanisms. Med Sci Sports Exerc 1994;26:432-439.

46 Doherty TJ, Vandervoort AA, Taylor AW, Brown WF: Effects of motor unit losses on strength in older men and women. J Appl Physiol (1985) 1993;74:868-874.

47 Brown M, Hasser EM: Complexity of age-related change in skeletal muscle. J Gerontol A Biol Sci Med Sci 1996;51:B117-B123.

48 Urbanchek MG, Picken EB, Kalliainen LK, Kuzon WM Jr: Specific force deficit in skeletal muscles of old rats is partially explained by the existence of denervated muscle fibers. J Gerontol A Biol Sci Med Sci 2001;56:B191B197.
49 Vitale G, Cesari M, Mari D: Aging of the endocrine system and its potential impact on sarcopenia. Eur J Intern Med 2016;35:10-15.

50 Baumgartner RN, Waters DL, Gallagher D, Morley JE, Garry PJ: Predictors of skeletal muscle mass in elderly men and women. Mech Ageing Dev 1999;107:123-136.

51 Snyder PJ, Bhasin S, Cunningham GR, Matsumoto AM, Stephens-Shields AJ, Cauley JA, Gill TM, Barrett-Connor E, Swerdloff RS, Wang C, Ensrud KE, Lewis CE, Farrar JT, Cella D, Rosen RC, Pahor M, Crandall JP, Molitch ME, Cifelli D, Dougar D, Fluharty L, Resnick SM, Storer TW, Anton S, Basaria S, Diem SJ, Hou X, Mohler ER 3rd, Parsons JK, Wenger NK, Zeldow B, Landis JR, Ellenberg SS, Testosterone Trials Investigators: Effects of testosterone treatment in older men. N Engl J Med 2016;374:611-624.

52 Messier V, Rabasa-Lhoret R, Barbat-Artigas S, Elisha B, Karelis AD, Aubertin-Leheudre M: Menopause and sarcopenia: a potential role for sex hormones. Maturitas 2011;68: 331-336.

53 Horstman AM, Dillon EL, Urban RJ, Sheffield-Moore M: The role of androgens and estrogens on healthy aging and longevity. J Gerontol A Biol Sci Med Sci 2012;67:11401152.

54 Sipila S, Narici M, Kjaer M, Pollanen E, Atkinson RA, Hansen M, Kovanen V: Sex hormones and skeletal muscle weakness. Biogerontology 2013;14:231-245.

55 Halfon M, Phan O, Teta D: Vitamin D: a review on its effects on muscle strength, the risk of fall, and frailty. Biomed Res Int 2015;2015: 953241.

56 Janssen HC, Samson MM, Verhaar HJ: Vitamin D deficiency, muscle function, and falls in elderly people. Am J Clin Nutr 2002;75: 611-615.

57 Churchward-Venne TA, Breen L, Phillips SM: Alterations in human muscle protein metabolism with aging: protein and exercise as countermeasures to offset sarcopenia. Biofactors 2014;40:199-205.

58 Timmerman KL, Lee JL, Dreyer HC, Dhanani S, Glynn EL, Fry CS, Drummond MJ, Sheffield-Moore M, Rasmussen BB, Volpi E: Insulin stimulates human skeletal muscle protein synthesis via an indirect mechanism involving endothelial-dependent vasodilation and mammalian target of rapamycin complex 1 signaling. J Clin Endocrinol Metab 2010;95: 3848-3857.

59 Jang HC: Sarcopenia, frailty, and diabetes in older adults. Diabetes Metab J 2016;40:182189.

60 Veldhuis JD, Liem AY, South S, Weltman A, Weltman J, Clemmons DA, Abbott R, Mulligan T, Johnson ML, Pincus S, et al: Differential impact of age, sex steroid hormones, and obesity on basal versus pulsatile growth hormone secretion in men as assessed in an ultrasensitive chemiluminescence assay. J Clin Endocrinol Metab 1995;80:3209-3222. 
61 Sattler FR: Growth hormone in the aging male. Best Pract Res Clin Endocrinol Metab 2013;27:541-555.

62 Volpato S, Bianchi L, Cherubini A, Landi F, Maggio M, Savino E, Bandinelli S, Ceda GP, Guralnik JM, Zuliani G, Ferrucci L: Prevalence and clinical correlates of sarcopenia in community-dwelling older people: application of the EWGSOP definition and diagnostic algorithm. J Gerontol A Biol Sci Med Sci 2014;69:438-446.

63 Dziki J, Badylak S, Yabroudi M, Sicari B, Ambrosio A, Stearns K, Turner N, Wyse A, Boninger M, Brown E, Rubin J: An acellular biologic scaffold treatment for volumetric muscle loss: results of a 13-patient cohort Study. Nature Regenerative Medicine 2016;1.

64 Brown BN, Ratner BD, Goodman SB, Amar S, Badylak SF: Macrophage polarization: an opportunity for improved outcomes in biomaterials and regenerative medicine. Biomaterials 2012;33:3792-3802.
65 Freytes DO, Martin J, Velankar SS, Lee AS, Badylak SF: Preparation and rheological characterization of a gel form of the porcine urinary bladder matrix. Biomaterials 2008;29: 1630-1637.

66 Wolf MT, Dearth CL, Sonnenberg SB, Loboa EG, Badylak SF: Naturally derived and synthetic scaffolds for skeletal muscle reconstruction. Adv Drug Deliv Rev 2015;84:208221.

67 Hinkle RT, Donnelly E, Cody DB, Bauer MB, Isfort RJ: Urocortin II treatment reduces skeletal muscle mass and function loss during atrophy and increases nonatrophying skeletal muscle mass and function. Endocrinology 2003;144:4939-4946.

68 Cleasby ME, Jamieson PM, Atherton PJ: Insulin resistance and sarcopenia: mechanistic links between common co-morbidities. J Endocrinol 2016;229:R67-R81.

69 Carlson CJ, Booth FW, Gordon SE: Skeletal muscle myostatin mRNA expression is fibertype specific and increases during hindlimb unloading. Am J Physiol 1999;277(2 pt 2): R601-R606.

70 Siriett V, Platt L, Salerno MS, Ling N, Kambadur R, Sharma M: Prolonged absence of myostatin reduces sarcopenia. J Cell Physiol 2006; 209:866-873.
71 Siriett V, Salerno MS, Berry C, Nicholas G, Bower R, Kambadur R, Sharma M: Antagonism of myostatin enhances muscle regeneration during sarcopenia. Mol Ther 2007;15: 1463-1470.

72 Tay L, Ding YY, Leung BP, Ismail NH, Yeo A, Yew S, Tay KS, Tan CH, Chong MS: Sex-specific differences in risk factors for sarcopenia amongst community-dwelling older adults. Age (Dordr) 2015;37:121.

73 White Z, Terrill J, White RB, McMahon C, Sheard P, Grounds MD, Shavlakadze T: Voluntary resistance wheel exercise from mid-life prevents sarcopenia and increases markers of mitochondrial function and autophagy in muscles of old male and female C57BL/6J mice. Skelet Muscle 2016;6:45.

74 Cezar CA, Roche ET, Vandenburgh HH, Duda GN, Walsh CJ, Mooney DJ: Biologicfree mechanically induced muscle regeneration. Proc Natl Acad Sci USA 2016;113:15341539. 